\title{
Treatment of isolated cervical facet fractures: a systematic review
}

\author{
Christopher K. Kepler, MD, MBA, ${ }^{1}$ Alexander R. Vaccaro, MD, PhD, MBA, ${ }^{1}$ Eric Chen, MD, ${ }^{2}$ \\ Alpesh A. Patel, MD, ${ }^{3}$ Henry Ahn, MD, PhD, ${ }^{4}$ Ahmad Nassr, MD, ${ }^{5}$ Christopher I. Shaffrey, MD, ${ }^{6}$ \\ James Harrop, MD, ${ }^{2}$ Gregory D. Schroeder, MD, ${ }^{1}$ Amit Agarwala, MD, ${ }^{7}$ Marcel F. Dvorak, MD, ${ }^{8}$ \\ Daryl R. Fourney, MD, ${ }^{9}$ Kirkham B. Wood, MD, ${ }^{10}$ Vincent C. Traynelis, MD, ${ }^{11}$ S. Tim Yoon, MD, PhD, ${ }^{12}$ \\ Michael G. Fehlings, MD, PhD, ${ }^{13}$ and Bizhan Aarabi, MD ${ }^{14}$
}

\begin{abstract}
1Department of Orthopaedic Surgery, Rothman Institute \& Thomas Jefferson University Hospital, Philadelphia, Pennsylvania; ${ }^{2}$ Department of Neurosurgery, Thomas Jefferson University Hospital, Philadelphia, Pennsylvania; ${ }^{3}$ Department of Orthopaedic Surgery, Northwestern Memorial Hospital, Chicago, Illinois; Departments of ${ }^{4}$ Orthopaedic Surgery and ${ }^{13}$ Neurosurgery, University of Toronto, Ontario, Canada; ${ }^{5}$ Department of Orthopaedic Surgery, Mayo Clinic, Rochester, Minnesota; ${ }^{6}$ Department of Neurosurgery, University of Virginia, Charlottesville, Virginia; ${ }^{7}$ Panorama Orthopedics \& Spine Center, Denver, Colorado; ${ }^{8}$ Department of Orthopaedic Surgery, University of British Columbia, Vancouver, British Columbia, Canada; ${ }^{9}$ Department of Neurosurgery, University of Saskatchewan, Saskatoon, Saskatchewan, Canada; ${ }^{10}$ Department of Orthopaedic Surgery, Massachusetts General Hospital, Boston, Massachusetts; ${ }^{11}$ Department of Neurosurgery, Rush University Medical Center, Chicago, Illinois; ${ }^{12}$ Department of Orthopaedic Surgery, Emory University, Atlanta, Georgia; and ${ }^{14}$ Department of Neurosurgery, University of Maryland, Baltimore, Maryland
\end{abstract}

OBJECTIVE In this clinically based systematic review of cervical facet fractures, the authors' aim was to determine the optimal clinical care for patients with isolated fractures of the cervical facets through a systematic review.

METHODS A systematic review of nonoperative and operative treatment methods of cervical facet fractures was performed. Reduction and stabilization treatments were compared, and analysis of postoperative outcomes was performed. MEDLINE and Scopus databases were used. This work was supported through support received from the Association for Collaborative Spine Research and AOSpine North America.

RESULTS Eleven studies with 368 patients met the inclusion criteria. Forty-six patients had bilateral isolated cervical facet fractures and 322 had unilateral isolated cervical facet fractures. Closed reduction was successful in $56.4 \%$ (39 patients) and $63.8 \%$ (94 patients) of patients using a halo vest and Gardner-Wells tongs, respectively. Comparatively, open reduction was successful in $94.9 \%$ of patients (successful reduction of open to closed reduction OR $12.8[95 \%$ Cl 6.1-26.9], $p<0.0001$ ); 183 patients underwent internal fixation, with an $87.2 \%$ success rate in maintaining anatomical alignment. When comparing the success of patients who underwent anterior versus posterior procedures, anterior approaches showed a $90.5 \%$ rate of maintenance of reduction, compared with a $75.6 \%$ rate for the posterior approach (anterior vs posterior OR 3.1 [95\% Cl 1.0-9.4], $p=0.05$ ).

CONCLUSIONS In comparison with nonoperative treatments, operative treatments provided a more successful outcome in terms of failure of treatment to maintain reduction for patients with cervical facet fractures. Operative treatment appears to provide superior results to the nonoperative treatments assessed.

http://thejns.org/doi/abs/10.3171/2015.6.SPINE141260

KEY WORDS systematic reviews; unilateral facet fracture; bilateral facet fracture; surgical reduction; closed reduction; cervical; trauma

$\mathrm{F}$ RACTURES involving facets of the cervical spine are a subset of cervical spine injuries. The mechanism that appears to be responsible for facet fractures is hyperextension combined with lateral bending and/or rotation, which may lead to disc disruption under tension, and a fracture of the facet under compression with resultant rotational instability. ${ }^{8}$ This investigation concerns isolated cervical facet fractures (either unilateral or bilateral) with or without associated displacement, meaning that the facet or facets at a single level are the only structures injured 
in a patient's cervical spine. Facet fractures represented $6.7 \%$ of all types of cervical spine fracture injuries treated at one institution over a 12 -year period. ${ }^{4}$ The articular facets play an important role in maintaining the stability of the cervical spine. Facet dislocation, especially a bilateral injury, is associated with a high rate of neurological injury, but there is controversy with regard to treatment of facet injuries without neurological injury or significant displacement. Many advocate nonoperative management of these injuries due to the possible complications associated with surgery and the possibility that a solid fusion may lead to earlier degeneration and adjacent-segment changes; however, others have suggested that fusion is indicated to reduce the risk of pseudarthrosis and/or delayed instability including deformity, persistent neurological deficit, and chronic neck pain.

The current literature addressing isolated facet fractures is sparse, and the decision to provide operative or nonoperative management depends on surgeon preference due to the lack of high-quality trials. There is no consensus for selection of nonoperative and operative management. ${ }^{1,2,4-12}$ Further evidence is needed to develop standardized treatment guidelines. This work seeks to provide insight regarding the optimal treatment options for this unique type of cervical spine injury. To accomplish this goal, a systematic review was conducted comparing operative and nonoperative treatment options based on clinical outcomes. The following research questions were addressed. 1) What is the best method of reduction of facet fractures? 2) What is the best method of stabilization of the injury? 3) Given that both nonoperative and operative treatments are commonly used and there is little guidance regarding the use of one versus the other, which treatment yields the best clinical outcome?

Prior to conducting the review, we hypothesized that operative treatments would yield the highest proportion of successful outcomes due to the use of direct visualization and instrumented stabilization. In terms of reduction of displacement, we hypothesized that visualization of the injury played a significant role in the return of the cervical spine to anatomical alignment, and that surgical intervention would result in fewer complications such as residual displacement or loss of reduction. With respect to stabilization of the injury, we felt that open techniques utilizing instrumented fusion would provide a greater degree of stability than any externally administered device, and surgical stabilization would have the greatest success in maintaining the reduced position of the injury. Thus, it was our opinion that operative management would yield superior outcomes in the treatment of isolated cervical facet fractures compared with nonsurgical treatment.

\section{Methods}

Optimal treatments for isolated cervical facet fractures were assessed through an evidence-based systematic literature review. Specifically, nonoperative and operative treatment methods of reduction and stabilization were compared, and the postoperative patient outcomes were analyzed.

Keywords were selected from Medical Subject Head- ings (MeSH), and a literature search was conducted using MEDLINE, Scopus, and Cochrane Database of Systematic Reviews. The initial search was refined to only include articles that would be of benefit regarding the query on isolated cervical facet fractures. The abstracts from the articles of the refined search were obtained and assessed for relevance to the study at hand.

Each abstract was reviewed independently by 2 authors (C.K.K. and E.C.) to identify articles that concentrated on the facet joint of the cervical spine (Fig. 1). Individual papers to relevant articles were obtained, and data pertaining to isolated fractures of the articular facets were collected for further analysis. Only articles that provided information regarding the treatment and outcomes of such injuries were included in the study. For each accepted article, the level of evidence was recorded, as well as the authors' final recommendation on patient treatment options.

\section{Clinical Inclusion and Exclusion Criteria}

The intention of this review is to describe treatment and outcomes of isolated facet fractures. Injuries included in the review include superior or inferior articular process fractures, fractures with separation of the lateral mass and both unilateral and bilateral fractures. Injuries excluded from this review include facet dislocations without fracture, facet subluxations without fracture, 2-level or more facet fractures, or injuries accompanied by other spinal fractures or dislocations.

\section{Literature Search}

The MEDLINE search terms included the queries "zygapophyseal joint" [MeSH] OR "facet joint" [MeSH] OR "articular process" OR "facet" OR "zygapophysis," which yielded 8053 articles. The search was limited to papers that were listed under the MeSH term "fractures, bone," reducing the number of articles to 515. A similar search was done using the Scopus database with the keywords "zygapophysis" OR "facet" OR "articular process," yielding 65,153 articles. The search was limited to papers published after 1970 that included the keyword "cervical," reducing the number of articles to 9091 . The search was further limited to papers that included the keyword "fracture," resulting in 581 remaining articles, and a total of 1096 articles.

\section{Study Inclusion and Exclusion Criteria}

The abstracts of the 1096 articles from database searches were obtained, and papers were further limited to studies with human subjects, written in the English language, and pertaining to injuries of the cervical spine. Based on title and abstract review, 98 potential articles were identified, and their full texts were obtained for analysis of data that matched the inclusion criteria. There were no randomized studies or large multicenter series comparing treatments and outcomes. Studies were excluded if they did not provide minimally required detail with regard to fracture classification, treatment (nonsurgical and surgical), and outcomes in the form of reduction, stabilization, or neurological deficits. Letters to the editor, commentaries, opinion articles, case reports, studies without clear 


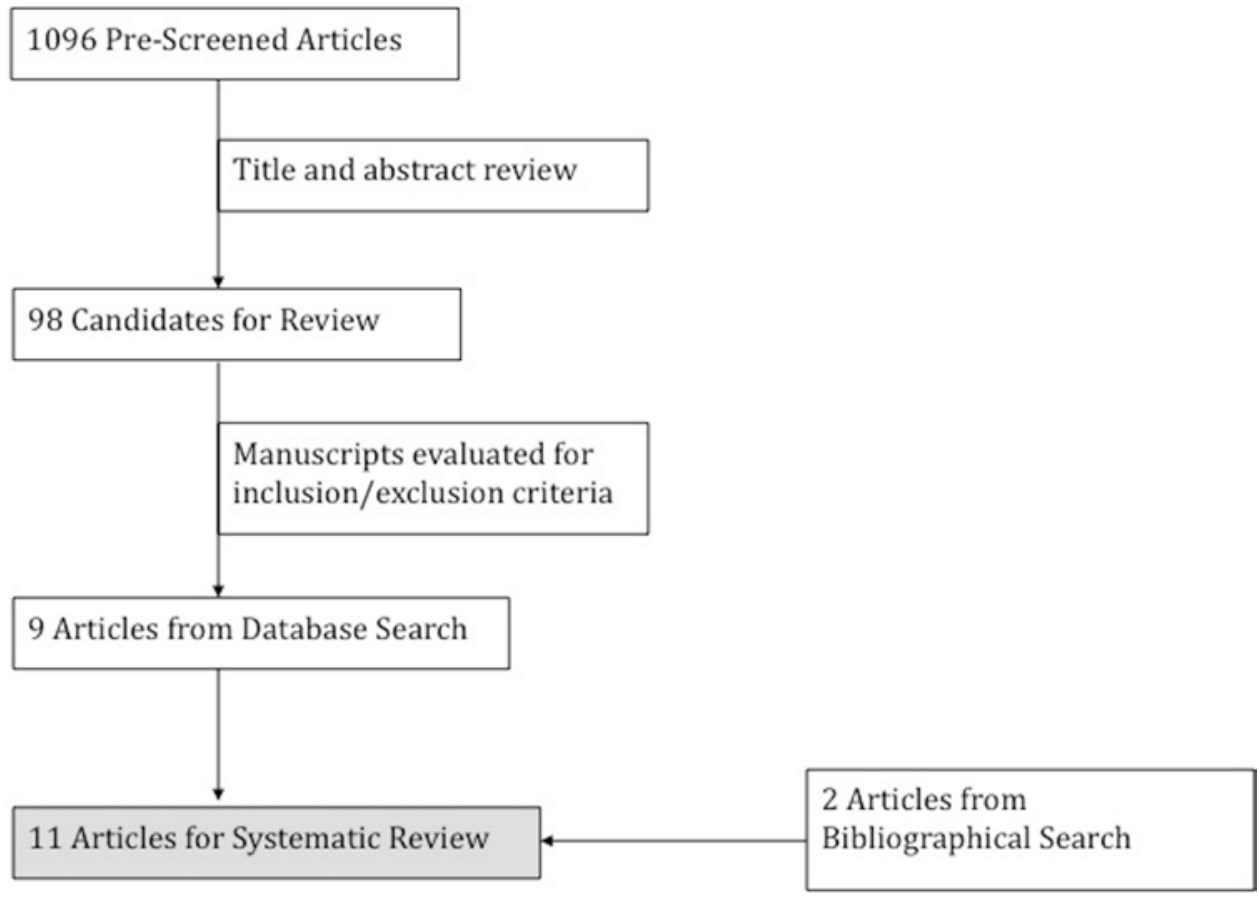

FIG. 1. Flowchart demonstrating the literature review results.

methodologies or containing fewer than 10 patients, and articles published prior to 1970 were also excluded. Eleven relevant papers were identified as matching the established inclusion criteria. The relevant papers were placed in evidentiary tables (Table 1).

\section{Statistical Analysis}

In each study, outcome measures were reported in the form of successful reduction and stabilization, pain, and persistent neurological deficits. Due to the low quality of evidence in the studies, and lack of a universal outcome measure when reporting patient data, a meta-analysis was not possible. The most universally used method of categorizing treatment success was the ability to reduce the facet fracture displacement to anatomical alignment, and the ability to stabilize the spine sufficiently to maintain anatomical alignment. Success rates and odds ratios were derived from the quantitative data obtained.

Due to the lack of widely accepted algorithms guiding the management of isolated cervical facet fractures with and without displacement, both nonoperative and operative modalities were not presented in all studies, as treatment was dictated by surgeon preference. Five studies focused exclusively on operative forms of treatment, and the authors made no attempt to nonsurgically reduce and stabilize the injuries without surgical intervention. Successful treatment was most often characterized as the ability to produce and maintain anatomical alignment while other outcome measures such as neurological deficit and achievement of fusion were not comprehensively reported and were not included in our analysis; our primary outcome for both operative and nonoperative treatment, therefore, was successful stabilization of the fracture without any need for further treatment. Injuries that were reduced using nonoperative methods and then stabilized surgically would be considered a failure of nonoperative treatment using this method of outcome scoring. Additionally, some studies did not have sufficient follow-up to address delayed complications following the treatment such as the development of kyphotic deformity and symptomatic disc space collapse. Other related factors such as the magnitude of subluxation or displacement, delay in treatment, associated injuries, and complications due to surgical intervention were also not consistently reported.

\section{Results \\ Patient Demographics}

A total of 368 patients were included in the analysis, of whom 46 suffered from bilateral isolated cervical facet fractures, and 322 from unilateral isolated cervical facet fractures. In the 291 cases where gender was specified, there were 209 males and 65 females. The frequencyweighted mean age was 35.6 years based on 311 cases where age was specified. The average follow-up period ranged from 3 months to 9 years.

Patients were collectively assigned to one of 2 categories in Table 1 . Patients who underwent primary surgical intervention were placed in the operative category while those who initially underwent conservative nonoperative treatment were placed in the nonoperative category. The ability to achieve radiographic alignment in the operative group was $90.8 \%$ compared with $43.2 \%$ of those patients that initially underwent conservative treatment, an operative to nonoperative OR of 13.0 (95\% CI 7.0-24.1, p $<0.0001)$. When assessing the subgroup of patients with unilateral facet fractures only, the treatment success rates of those patients in the operative group was $87.9 \%$ compared with $42.6 \%$ of those patients who initially under- 
TABLE 1. Evidentiary table of generalized treatment and outcomes

\begin{tabular}{|c|c|c|c|c|c|c|c|}
\hline Authors \& Year & $\begin{array}{l}\text { Level of } \\
\text { Evidence }\end{array}$ & $\begin{array}{l}\text { No. of } \\
\text { Pts }\end{array}$ & $\begin{array}{l}\% \text { Male } \\
\text { Pts }\end{array}$ & $\begin{array}{l}\text { Follow-Up } \\
\text { (mos) }\end{array}$ & $\begin{array}{l}\text { No. of Nonop } \\
\text { Reduction/ } \\
\text { Stabilization } \\
\text { (failures) }\end{array}$ & $\begin{array}{l}\text { No. of Op } \\
\text { Reduction/ } \\
\text { Stabilization } \\
\text { (failures) }\end{array}$ & Notes \\
\hline Ngo et al., 2012 & IV & 11 & 0.81 & & & 11 & \\
\hline Lee \& Sung, 2009 & IV & 14 & 0.77 & 12 & $7\left(6^{*}\right)$ & $13(2)$ & \\
\hline Rabb et al., 2007 & IV & 25 & 0.64 & 11.5 & & $25(1)$ & \\
\hline $\begin{array}{l}\text { Harrington \& Park, } \\
\quad 2007\end{array}$ & IV & 22 & 0.68 & $>1.75$ & & $22(4)$ & \\
\hline Spector et al., 2006 & IV & 24 & 0.54 & 3 & $24\left(5^{\star}\right)$ & 5 & \\
\hline Hadley et al., 1992 & IV & 66 & 0.8 & 18 & $\begin{array}{l}59\left(28^{*}, 2 \text { nd failure }\right. \\
\text { in } 3 \text { pts })\end{array}$ & 32 & \\
\hline Beyer et al., 1991 & III & 34 & $\begin{array}{l}\text { Mostly } \\
\text { male }\end{array}$ & $\begin{array}{l}\text { Nonop 108; } \\
\text { op } 78\end{array}$ & $24(18)$ & $10(4)$ & \\
\hline Lifeso \& Colucci, 2000 & IV & 47 & 0.86 & 24 & $18(18)$ & $29(5)$ & \\
\hline Dvorak et al., 2007 & III & 41 & 0.8 & 29.7 & 17 & 24 & Outcome measure: SF-36 PCS \\
\hline Koivikko et al., 2004 & III & 57 & & $>3$ & 22 & 35 & Qualitative outcome measures \\
\hline $\begin{array}{l}\text { Shanmuganathan et al., } \\
1994\end{array}$ & IV & 27 & 0.78 & & & 27 & \\
\hline \multicolumn{5}{|c|}{ Total (excluding qualitative data) } & $132(75)$ & $174(16)$ & $\begin{array}{l}\text { Total: \% success nonop 43.2, op 90.8; op/ } \\
\text { nonop OR for success } 13.0(95 \% \mathrm{Cl} \\
\text { 7.0-24.1), } p<0.0001\end{array}$ \\
\hline \multicolumn{5}{|c|}{ Unilateral fractures (excluding qualitative data) } & $101(58)$ & $107(13)$ & $\begin{array}{l}\text { Unilateral: \% success nonop 42.6, op 87.9; } \\
\text { op/nonop OR for success; } 9.8 \text { (95\% Cl } \\
\text { 4.8-19.7), } p<0.0001\end{array}$ \\
\hline
\end{tabular}

Pts = patients; SF-36 PFS = 36-Item Short-Form Health Survey Physical Component Summary.

${ }^{*}$ Nonoperative failures underwent delayed surgical management.

went conservative treatment, with an operative to nonoperative OR of 9.8 (95\% CI 4.8-19.7, p < 0.0001).

\section{Treatment Options}

Treatment for cervical facet fractures varied from study to study, with surgeon preference playing a substantial role in determining the course of treatment. Regardless of the specific treatment rendered, a 2-step process was universally followed to treat the injury. First, the facet displacement was reduced. This was performed either nonoperatively using traction through a halo ring or Gardner-Wells tongs, or surgically via open reduction. Facet fractures that could not be reduced using closed techniques were generally reduced surgically, although this could not be verified in every case. Second, the stability of the cervical spine was addressed. Patients who underwent successful closed reduction of the cervical spine either continued conservative treatment with closed immobilization or underwent surgical fusion. Those who underwent open reduction were universally stabilized via surgical fusion, regardless of whether conservative management was initially attempted. Different forms of treatment were analyzed to determine if there was evidence of differential outcome based on form of treatment, but insufficient information was available to perform meaningful subanalysis; the only comparison that can be derived is between operative and nonoperative management techniques.

In 340 patients for whom the method of treatment was specified, various methods of reduction were attempted. In 41 cases, treatment was not described further beyond reporting whether reduction and stabilization was accomplished by operative or nonoperative methods. Outcomes for 98 patients were reported only in qualitative terms, and 3 patients did not undergo any operative or nonoperative attempt at reduction. A total of 154 patients underwent nonoperative reduction attempts with an overall success rate of $59.1 \%$ (Table 2). In this subset of patients who underwent closed reduction, the successful reduction rates using the halo vest and Gardner-Wells tongs were $56.4 \%$ (39 patients) and 63.8\% (94 patients), respectively. In contrast, 175 patients were treated with primary surgical intervention, resulting in successful open reduction in $94.9 \%$ of patients. The calculated OR of successful reduction of open reduction to closed reduction techniques was 12.8 (95\% CI 6.1-26.9, $\mathrm{p}<0.0001)$. When assessing only unilateral facet fractures, $50.0 \%$ (118 patients) of closed reduction attempts were successful compared with a success rate of $86.5 \%$ (96 patients) for open reduction attempts. The calculated OR of successful reduction of open reduction to closed reduction techniques for unilateral injuries was 6.4 (95\% CI 3.2-12.7, p < 0.0001).

In general, patients who sustained injuries for which closed reduction was attempted and failed underwent open reduction and stabilization. All 175 patients in whom surgical reduction was performed also underwent surgical stabilization. Patients who underwent successful closed 
TABLE 2. Reduction technique*

\begin{tabular}{|c|c|c|c|}
\hline Variable & $\begin{array}{c}\text { No. of } \\
\text { Attempts } \\
\text { (failures) }\end{array}$ & $\begin{array}{c}\text { Success } \\
\text { Rate \% }\end{array}$ & $\begin{array}{c}\text { OR }(95 \% \mathrm{Cl}) \\
\text { p Value }\end{array}$ \\
\hline Extension manipulation & 8 & 100 & \\
\hline Halo vest & $39(17)$ & 56.4 & \\
\hline Hard collar & $12(12)$ & 0 & \\
\hline Gardner-Wells tongs & $94(34)$ & 63.8 & \\
\hline Spontaneous reduction & 1 & 100 & \\
\hline Total closed reduction & $154(63)$ & 59.1 & \\
\hline $\begin{array}{l}\text { Total open reduction (in- } \\
\text { cluding failed closed } \\
\text { reduction attempts) }\end{array}$ & $175(9)$ & 94.9 & \\
\hline $\begin{array}{l}\text { Total open:closed reduction } \\
\text { OR }\end{array}$ & & & $\begin{array}{c}12.8(6.1-26.9) \\
<0.0001\end{array}$ \\
\hline Unilateral closed reduction & $118(59)$ & 50.0 & \\
\hline Unilateral open reduction & $96(13)$ & 86.5 & \\
\hline $\begin{array}{l}\text { Unilateral open:closed } \\
\text { reduction OR }\end{array}$ & & & $\begin{array}{l}6.4(3.2-12.7) \\
<0.0001\end{array}$ \\
\hline
\end{tabular}

* Treatment was unspecified in 41 patients.

reduction either continued their nonoperative treatment or underwent surgical stabilization of the spine via instrumented fusion. A total of 183 patients underwent internal fixation, with an $87.2 \%$ (148 patients) success rate in maintaining anatomical alignment (Table 3 ). The majority of failures during attempts at open stabilization came from the posterior cervical fusion approach, where 9 of 37 patients $(24.3 \%)$ did not maintain anatomical alignment or exhibited other complications such as late kyphosis related to vertebral or disc collapse. When comparing the success of patients who underwent anterior versus posterior procedures, anterior approaches showed a 90.5\% (63 patients) rate of maintenance of reduction, while posterior approaches showed a $75.6 \%$ rate of maintenance of reduc-

TABLE 3. Internal stabilization technique

\begin{tabular}{lccc}
\hline \multicolumn{1}{c}{ Treatment Type } & $\begin{array}{c}\text { No. of } \\
\text { Attempts } \\
\text { (failures) }\end{array}$ & $\begin{array}{c}\text { Maintaining } \\
\text { Reduction }\end{array}$ & $\begin{array}{c}\text { OR (95\% Cl), } \\
\text { p Value }\end{array}$ \\
\hline Posterior cervical fusion & $37(9)$ & 75.6 & \\
\hline Anterior cervical fusion & $63(6)$ & 90.5 & \\
\hline $\begin{array}{l}\text { Anterior \& posterior cervical } \\
\text { fusion }\end{array}$ & $11(3)$ & 72.7 & \\
\hline $\begin{array}{l}\text { Nonspecific internal fixation } \\
\text { Total surgical intervention }\end{array}$ & $37(1)$ & 97.3 & \\
\hline $\begin{array}{l}\text { Anterior/posterior approach } \\
\text { OR }\end{array}$ & & 87.2 & \\
\hline $\begin{array}{l}\text { Unilateral posterior cervical } \\
\text { fusion }\end{array}$ & $25(9)$ & 64.0 & \\
\hline $\begin{array}{l}\text { Unilateral anterior cervical } \\
\text { fusion }\end{array}$ & $54(4)$ & 92.6 & \\
\hline $\begin{array}{l}\text { Unilateral (internal fixation) } \\
\text { Unilateral anterior/posterior } \\
\text { approach OR }\end{array}$ & $79(13)$ & 83.5 & \\
\hline
\end{tabular}

tion (37 patients). The calculated OR of maintenance of reduction for anterior versus posterior approaches was $3.1(95 \%$ CI $1.0-9.4, \mathrm{p}=0.05)$. When only unilateral injuries were taken into consideration, posterior fusion had a $64.0 \%$ (25 patients) success rate, while anterior fusion had a $92.6 \%$ (54 patients) success rate of maintenance of reduction. The total success rate for unilateral facet fractures treated with internal stabilization was $83.5 \%$ (79 patients). The calculated OR describing the anterior to posterior approaches for unilateral facet fractures was 7.0 (95\% CI $1.9-25.9, \mathrm{p}=0.0034)$.

\section{Discussion}

In our review of treatment of isolated cervical facet fractures, we found that operative treatment yielded the greatest likelihood of successful anatomical reduction (90.8\% of 174 patients) compared with the nonoperative reduction techniques (43.2\% of 132 patients). The calculated OR of 13.0 (95\% CI 7.0-24.1, p < 0.0001) comparing operative to nonoperative management suggests operative management is superior for restoration of anatomical alignment after facet fracture, findings that must be balanced against the risk of surgical complications.

With respect to maintenance of reduction on follow-up, open reduction and stabilization had the highest proportion of positive outcomes ( $94.9 \%$ out of 175 patients), while nonoperative methods of management had lower rates of maintenance of reduction, including reduction via traction and bracing (63.8\% of 94 patients) and traction followed by stabilization using a halo vest (56.4\% of 39 patients). Cumulatively, conservative reduction had a positive outcome rate in $59.1 \%$ of 154 patients). The calculated OR for failure to maintain reduction when comparing operative to nonoperative methods of reduction and stabilization was 12.8 (95\% CI 6.1-26.9, p < 0.0001), indicating a statistically significant increased relative risk of failure for patients undergoing conservative reduction of facet fractures. ${ }^{2}$

When comparing methods of operative stabilization, combined anterior and posterior techniques demonstrated a $72.7 \%$ rate of maintenance of reduction in a small subset of 11 patients. Anterior approaches resulted in a $90.5 \%$ success rate in 63 patients. Posterior fusion techniques had a lower success rate of $75.6 \%$ of maintenance of reduction in a subset of 37 patients. This lower success rate may be misleading as the posterior wire and cable stabilization techniques used for posterior stabilization or in combined anterior/posterior procedures in many studies have since been largely discarded in favor of lateral mass screw techniques that offer more robust stabilization. The calculated OR between anterior and posterior fusion stabilization techniques was 3.1 (95\% CI 1.0-9.4, p = 0.052), indicating a statistically nonsignificant increase in relative risk of failure to achieve or maintain reduction for those patients that underwent posterior over anterior procedures. Lifeso and Colucci reported that in their initial 11-patient subset that underwent posterior fusion procedures (6 with wiring techniques and 5 with lateral mass screw fixation), 9 led to successful reduction. ${ }^{8}$ However, at 2-year follow-up, 3 of the "successes" exhibited late-developing kyphosis of more than $10^{\circ}$, all purportedly related to anterior disc 
space collapse despite the presence of solid posterior fusion. The same study reported a $100 \%$ success rate in 18 patients treated with anterior cervical fusion, with no signs of kyphosis or disc collapse at last follow-up. Another consideration is that studies with shorter follow-up times may not have detected such late complications. Success rates may be overestimated in general due to lack of sufficient follow-up to detect late complications of fusion procedures, a feature of the spine trauma literature that must be considered as a limitation of this paper. In addition, the lack of detailed treatment and outcome data may have biased reported outcome toward higher rates of success. Finally, although this review found that anterior-approach surgery had a nonsignificant advantage over posteriorapproach surgery, anatomical characteristics must be considered during operative planning; anterior-only surgery has been associated with inferior results in patients with fracture comminution or superior endplate fracture. ${ }^{2}$

As with all invasive procedures, there are risks of surgical complications. While it was the initial intention of the authors to include complications in the analysis, the failure of studies to consistently report complications made any meaningful analysis of complications impossible. In the case of open reduction and stabilization, there were reports of general complications associated with spinal surgery but also with spinal cord injury, such as ventilator pneumonia, infection, and wound drainage, ${ }^{5}$ however, these complications were rarely included in the nonoperative cohorts. To the extent that patients with spinal cord injury who were treated without surgery are at increased risk of these complications, the surgical intervention may not be solely responsible for these complications. In addition, Lifeso and Colucci reported injury-specific complications such as late kyphosis and late disc collapse that were observed late in the 2-year follow-up in patients who were initially reported as having positive outcomes. ${ }^{8}$ Successful closed reduction was also not without complication, as ankylosing facets and neck pain due to residual displacement were found in patients who underwent closed reduction and stabilization. ${ }^{5,8}$ Conservative stabilization was found in one study to poorly maintain reduced displacement. ${ }^{8} \mathrm{~A}$ facet fracture nonunion rate of $23 \%$ was also found in one study in nonoperatively treated patients. ${ }^{4}$

Several studies that compared operative to nonoperative treatment of isolated facet fractures presented standardized patient-derived outcome measures at follow-up visits. In these studies, it was concluded that surgical treatment resulted in better alignment, and that late neck pain was correlated with residual displacement, a complication more commonly seen in patients receiving conservative treatment. ${ }^{6}$ In contrast, Dvorak et al. observed that patients in the nonoperative group had statistically significant increases of 6.70 and 9.34 in 36-Item Short-Form Health Survey Physical Component Summary and bodily pain scores, respectively, compared with the operative group. ${ }^{2}$

This study has significant limitations, including all of those that are inherent to a systematic review. The recommendations from this study are based completely on all of the available medical literature, but these are mainly case series with few comparative studies. Additionally, studies included in the analysis span a wide time frame (1991-
2012), and significant surgical advances in spine surgery have occurred during this time frame. The wide adoption of lateral mass fixation in the cervical spine has likely improved the ability of surgeons to maintain anatomical alignment using a posterior-only approach. Similarly, advancements in anterior cervical plating may improve the results from patients undergoing anterior surgery. Combing the changes in surgical technique and the failure of many studies to report operative details, the current study also could not address if one surgical technique leads to a decrease in the number of levels that need to be fused. In our personal experience, we have found that advances in surgical techniques allow for excellent results with a single-level fusion in most cases. The advent of lateral mass fixation allows for a single-level posterior cervical fusion to maintain anatomical alignment while restoring the posterior tension band that is often disrupted in these injuries. Similarly, in cases with an intact ligamentous tension band, a single-level ACDF is often sufficient. Additionally, all but one of the studies included were published prior to the "Surgical Timing in Acute Spinal Cord Injury Study," which clearly demonstrates improved results with urgent decompression of the spinal cord. ${ }^{3}$ Because of this, the timing of reduction in both the operative and nonoperative groups varied widely, and it was not reported at all in other studies. This made a meaningful analysis on the effect of the treatment on neurological recovery impossible.

Other limitations to the study include that we were unable to report the effect of comorbidities on treatment outcomes, as the details of individual patient comorbidities was rarely reported. Similarly, the heterogeneity in the reporting of complications made a meaningful analysis of this outcome impossible. While complications with surgery were often reported, there are also significant complications associated with hard collars and halo orthoses that were not. One final limitation to this review is that the included studies focus primarily on misaligned fractures, but the definition of an acceptable reduction is not uniform across the studies. Therefore, it is possible that some patients with failed nonoperative care in one study may not have been considered to have had a failure in other studies. Additionally, extrapolation of the results of the current study to nondisplaced fractures is limited. The best available guidance in the treatment of nondisplaced cervical facet fractures comes from a manuscript by Spector et al., when they identified 2 major risk factors for failure of nonoperative treatment of nondisplaced cervical facet fractures. At-risk fractures include fractures that are more than $40 \%$ of the absolute height of the intact lateral mass, and fractures with an absolute height of more than $1 \mathrm{~cm} .{ }^{12}$

\section{Conclusions}

The systematic review offers answers to our 3 primary research questions.

1) What is the best method of reduction of facet fracturedislocations? While closed methods of reduction have been reported to be successful, open methods are more successful either as a primary means of reduction or when closed methods have failed to either reduce a fracture or maintain reduction. The risks of operative 
treatment should be considered in the decision-making process as well as the reported safety of closed reduction methods. As such, the review supports a primary attempt at closed reduction in the appropriate clinical setting with open reduction in those patients who are not candidates for closed reduction or in those in whom closed reduction has failed.

2) What is the best method of stabilization of the injury? After reduction has been achieved, an anterior or a combined anterior-posterior approach for treatment provides better stabilization than a posterior-only approach, although this is based on a small number of cases with respect to the anteroposterior approach. Limitations in the reported literature as well as the use of more current rigid, segmental posterior instrumentation may ultimately support a posterior-only approach.

3) Given that both nonoperative and operative treatments are commonly used and there is little guidance regarding the use of one versus the other, which treatment yields the best clinical outcome? Operative treatment has been shown to yield better radiographic outcomes (alignment, reduction). There is insufficient evidence to allow for a comparison between treatments based on clinical outcome measures. Treatment, therefore, is best guided based on the individual patient's neurological status, injury status, and surgical risk.

Although a review of the literature suggests a statistically significant advantage in terms of successful reduction and maintenance of reduction for surgical treatment of isolated facet fractures compared with nonoperative management, this finding must be carefully considered, given both the possibility of higher risk associated with surgical management as well as the relatively low quality of the available literature. Several important considerations could not be studied by this review due to limited reporting of such clinical variables such as magnitude of fracture displacement and treatment complications. Further prospective studies to compare results after operative and nonoperative management are necessary to provide definitive guidance regarding the best method of treatment. Furthermore, complications of operative and nonoperative treatment must be reported to compare the associated risk and may identify patient subpopulations for which treatment guidelines may differ, particularly with respect to treatment of facet fractures in elderly patients with poor tolerance for prolonged cervical spine immobilization.

\section{References}

1. Beyer CA, Cabanela ME, Berquist TH: Unilateral facet dislocations and fracture-dislocations of the cervical spine. J Bone Joint Surg Br 73:977-981, 1991

2. Dvorak MF, Fisher CG, Aarabi B, Harris MB, Hurbert RJ, Rampersaud YR, et al: Clinical outcomes of 90 isolated unilateral facet fractures, subluxations, and dislocations treated surgically and nonoperatively. Spine (Phila Pa 1976) 32:3007-3013, 2007

3. Fehlings MG, Vaccaro A, Wilson JR, Singh A, W Cadotte D, Harrop JS, et al: Early versus delayed decompression for traumatic cervical spinal cord injury: results of the Surgical Timing in Acute Spinal Cord Injury Study (STASCIS). PLoS One 7:e32037, 2012
4. Hadley MN, Fitzpatrick BC, Sonntag VK, Browner CM: Facet fracture-dislocation injuries of the cervical spine. Neurosurgery 30:661-666, 1992

5. Harrington JF Jr, Park MC: Single level arthrodesis as treatment for midcervical fracture subluxation: a cohort study. J Spinal Disord Tech 20:42-48, 2007

6. Koivikko MP, Myllynen P, Santavirta S: Fracture dislocations of the cervical spine: a review of 106 conservatively and operatively treated patients. Eur Spine J 13:610-616, 2004

7. Lee SH, Sung JK: Unilateral lateral mass-facet fractures with rotational instability: new classification and a review of 39 cases treated conservatively and with single segment anterior fusion. J Trauma 66:758-767, 2009

8. Lifeso RM, Colucci MA: Anterior fusion for rotationally unstable cervical spine fractures. Spine (Phila Pa 1976) 25:2028-2034, 2000

9. Ngo LM, Aizawa T, Hoshikawa T, Tanaka Y, Sato T, Ishii Y, et al: Fracture and contralateral dislocation of the twin facet joints of the lower cervical spine. Eur Spine J 21:282-288, 2012

10. Rabb CH, Lopez J, Beauchamp K, Witt P, Bolles G, Dwyer A: Unilateral cervical facet fractures with subluxation: injury patterns and treatment. J Spinal Disord Tech 20:416-422, 2007

11. Shanmuganathan K, Mirvis SE, Levine AM: Rotational injury of cervical facets: CT analysis of fracture patterns with implications for management and neurologic outcome. AJR Am J Roentgenol 163:1165-1169, 1994

12. Spector LR, Kim DH, Affonso J, Albert TJ, Hilibrand AS, Vaccaro AR: Use of computed tomography to predict failure of nonoperative treatment of unilateral facet fractures of the cervical spine. Spine (Phila Pa 1976) 31:2827-2835, 2006

\section{Disclosure}

The authors report that AOSpine and the Association for Collaborative Spine Research provided resources to help with this paper. The authors report the following. Dr Schroeder: funding from Medtronic for travel to meetings. Dr. Kepler: consultant for Healthgrades. Dr. Vaccaro: consultant for Medtronic, Stryker Spine, Globus, Stout Medical, Gerson Lehrman Group, Guidepoint Global, Medacorp, Innovative Surgical Design, and Orthobullets; expert testimony for Ellipse; service on scientific advisory board/board of directors/service on committees for innovative surgical design for Spinicity, AOSpine, and Association of Collaborative Spine Research; royalties from Thieme, Jaypee, Elsevier, Taylor Francis, Aesculap, Globus, Medtronic, Stryker, and Biomet Spine; institutional support from Cerapedics; owns stock in Spine Medica, Computational Biodynamics, Progressive Spinal Technologies, Spinology, Small Bone Innovations, Cross Current, In Vivo, Flagship Surgical, Advanced Spinal Intellectual Properties, Cytonics, Bonovo Orthopaedics, Electrocore, Gamma Spine, Location Based Intelligence, FlowPharma, R.S.I., Replication Medica, Globus, Stout Medical, Rothman Institute and Related Properties, Innovative Surgical Design, Spinicity; and Paradigm Spine. Dr. Patel: consultant for Biomet, DePuy (A Johnson \& Johnson Company), Stryker, Zimmer, GE Healthcare Nocimed, Amedica, Ulrich, and Relievant; direct stock ownership in Amedica, Trinity Orthopaedics, Cytonics, Nocimed, and Vital 5; IP royalties from Amedica and Ulrich Medical USA; publishing royalties, financial or material support from Springer; board or committee member AAOS, American College of Surgeons, American Orthopaedic Association, AOSpine North America, Cervical Spine Research Society, Indo-American Spine Alliance, Lumbar Spine Research Society, and North American Spine Society; and editorial or governing board of Journal of the American Academy of Orthopaedic Surgeons, Surgical Neurology International, and Wolters Kluwer Health-Lippincott Williams \& Wilkins. Dr. Nassr: grants from AOSpine, CSRS, 


\section{K. Kepler et al.}

and OREF; and fellowship support from AOSpine. Dr. Harrop: consultant for DePuy and Bioventus; grants from NACTN; and fellowship Support from AOSpine NA. Dr. Shaffrey: consultant for Biomet, Globus, Medtronic, NuVasive, and Stryker; stock ownership in NuVasive; patent holder with Biomet, Medtronic, and NuVasive; royalties from Biomet and Medtronic; grants from NIH, Department of Defense, AO, NREF, and NACTN; fellowship support: NREF, AO, and UVa; non-study-related support form ISSG and DePuy Synthes. Dr. Agarawala: consultant for Medtronic. Dr. Fourney: research support from Asubio Pharmaceuticals; grants from Canadian Institute of Health Research, Rick Hansen Foundation, Saskatchewan Health Research Foundation, Royal University Hospital, and AOSpine, and fellowship support from AOSpine. Dr. Wood: stock ownership in TranS1; other financial or material support from Globus Medical and OREF; research support from K2M; editorial or governing board of Spine and Spinal Deformity; and fellowship support form Synthes. Dr. Traynelis: consultant for, royalties from, patent holder with, and research support from Medtronic; grants from NIH; and fellowship support from Globus. Dr. Yoon: consultant for Meditech Advisors, and Stryker; and intellectual property royalties from Stryker and Meditech; stock ownership in
Alphatec Spine, Meditech Advisors, Medyssey, and Phygen; editorial or governing board for American Journal of Orthopedics, Journal of Bone and Joint Surgery-American, Journal of Orthopaedic Research, The Spine Journal, Spine; and board or committee member of International Society for the Study of the Lumbar Spine.

\section{Author Contributions}

Conception and design: all authors. Acquisition of data: Schroeder, Kepler, Vaccaro, Chen. Analysis and interpretation of data: Schroeder, Kepler, Vaccaro. Drafting the article: Schroeder,

Kepler, Vaccaro, Chen. Critically revising the article: Schroeder, Kepler, Vaccaro, Patel, Ahn, Nassr, Shaffrey, Harrop, Agarwala, Dvorak, Fourney, Wood, Traynelis, Yoon, Fehlings, Aarabi. Reviewed submitted version of manuscript: Schroeder, Kepler, Vaccaro, Patel, Ahn, Nassr, Shaffrey, Harrop, Agarwala, Dvorak, Fourney, Wood, Traynelis, Fehlings, Aarabi. Statistical analysis: Kepler.

\section{Correspondence}

Gregory D. Schroeder, 925 Chesnut St., 5th Fl., Philadelphia, PA 19107. email: gregdschroeder@gmail.com. 